\title{
Valor Nutritivo das Silagens de Capim-Elefante com Diferentes Níveis de Subprodutos da Indústria do Suco de Caju'
}

\section{Ana Cristina Holanda Ferreira ${ }^{2}$, José Neuman Miranda Neiva ${ }^{3}$, Norberto Mário Rodriguez ${ }^{4}$, Raimundo Nonato Braga Lôbo ${ }^{5}$, Vânia Rodrigues de Vasconcelos ${ }^{6}$}

RESUMO - O trabalho foi conduzido com o objetivo de se avaliar o valor nutritivo das silagens de capim-elefante com adição de $0,12,24,36$ e $48 \%$ de bagaço de caju (subproduto da agroindústria de suco de caju). Utilizou-se o delineamento inteiramente casualizado com quatro repetições. Após 82 dias, os silos foram abertos e coletadas amostras para determinação dos teores de matéria seca (MS), proteína bruta (PB), fibra em detergente neutro (FDN), fibra em detergente ácido (FDA), hemicelulose (HEM), $\mathrm{pH}^{\mathrm{H}}$ e níveis de $\mathrm{N}-\mathrm{NH}{ }_{3}$ das silagens. A adição de bagaço de caju (BC) diminuiu os valores de $\mathrm{pH}$ e $\mathrm{N}^{-\mathrm{NH}_{3}}$ e elevou os teores de $\mathrm{PB}$ das silagens. Os teores de FDA e HEM não diferiram entre os tratamentos. Concluiu-se que o bagaço de caju melhora o valor nutritivo da silagem e proporciona melhor conservação da massa ensilada.

Palavras-chave: Anacardium occidentale, fermentação, Pennisetum purpureum

\section{Nutritive Value of Elephantgrass Silage Added By-Products from the Cashew Juice Industry}

\begin{abstract}
This trial was conducted with the objective of evaluating the nutritive value of the silage of elephantgrass by the addition of $0,12,24,36$ and $48 \%$ of cashew bagasse (by-product of the cashew juice agro-industry). A completely randomized design with four replicates was used. After 82 days, the silos were opened and samples were collected for determination of dry matter (DM), crude protein (CP), neutral detergent fiber (NDF), acid detergent fiber (ADF), hemicellulose (HEM), $\mathrm{pH}$ and levels of $\mathrm{N}^{-\mathrm{NH}} \mathrm{H}_{3}$ of the silage. The addition of the cashew bagasse (BC) decreased the $\mathrm{pH}$ and $\mathrm{N}-\mathrm{NH}_{3}$ values and increased the $\mathrm{PB}$ grade of the silage. The level of ADF and HEM did not change in function of different additions. It was concluded that the cashew bagasse improves the nutritive value of the silage and provides better conservation of silage.
\end{abstract}

Key Words: Anacardium occidentale, fermentation, Pennisetum purpureum

\section{Introdução}

Na região nordeste do Brasil, a produção de forragem apresenta forte estacionalidade, em decorrência, principalmente, da má distribuição das chuvas. Este fato leva ao fornecimento de forragens de baixa qualidade aos animais, determinando inadequado consumo de nutrientes e comprometendo a produção animal. Uma das maneiras de se alterar o quadro vigente é desenvolver alternativas para o aproveitamento de subprodutos da agroindústria disponíveis no período crítico do ano.

No Ceará, pode-se destacar o caju (Anacardium occidentale L.) como uma das principais frutas cultivadas. $\mathrm{Na}$ industrialização do pseudofruto do caju para produção de sucos, são gerados em torno de $40 \%$ de subproduto (bagaço do pseudofruto do caju). Segundo Holanda et al. (1996), a produção de pedúnculos chega a mais de 1 milhão de toneladas/ ano, ressaltando que esta produção se concentra na estação seca do ano (julho a janeiro), período que se caracteriza pela menor disponibilidade de forragem na região, tanto quantitativa como qualitativamente.

Os subprodutos resultantes da extração do suco do pseudofruto do caju e dos pedúnculos imprestáveis para o consumo humano, podem ser utilizados na alimentação animal, ao natural, como farelo de polpa de caju (Lavezzo, sd), e na forma de silagem, que representa uma maneira de melhorar o valor nutritivo da polpa de caju, uma vez que o produto apresenta

\footnotetext{
1 Pesquisa financiada pela CAPES/PROCAD, pelo CNPq e Banco do Nordeste.

2 Aluna de doutorado da Universidade Federal de Minas Gerais-UFMG. Bolsista da CAPES. E.mail: anacristinahf@hotmail.com

3 Professor da Universidade Federal do Tocantins - UFT, Rua Humberto Campos, 508, B. São João, Araguaina - TO. Bolsista do CNPq.

Autor para correspondências. E.mail: zeneuman@uft.edu.br

4 Professor da Universidade Federal de Minas Gerais-UFMG. Bolsista do CNPq. E.mail: norberto@vet.ufmg.br

5 Pesquisador da Embrapa-Caprinos. Bolsista do CNPq. E.mail: lobo@cnpc.embrapa.br

6 Professora da Universidade Federal do Piauí. E.mail: vânia@ufpi.br
} 
altos teores de umidade e fibra, que podem limitar a utilização direta na alimentação animal (Awolumate, 1983). Desse modo, a busca pela utilização mais adequada desse subproduto é de extrema importância tanto para formulação de dietas para ruminantes, como para preservação do meio ambiente.

No Brasil, uma das gramíneas possíveis de serem utilizadas na ensilagem do bagaço do caju é o capimelefante. Segundo Faria et al. (1995/96), a ensilagem do capim-elefante minimiza o problema da estacionalidade de produção de forragem que, no caso da referida gramínea, tem $80 \%$ da produção no período chuvoso.

Deve-se destacar, entretanto, que o capim-elefante apresenta limitações. Segundo Lavezzo (1985), quando o capim-elefante atinge seu "equilíbrio nutritivo", ou seja, mostra boa produção por área e bom valor nutritivo - que ocorre quando o corte para ensilagem é realizado com 50-60 dias de crescimento -, apresenta alto teor de umidade, baixo teor de carboidrato solúvel e alto poder tampão, fatores que, em conjunto, podem influenciar negativamente o processo fermentativo. Segundo McDonald (1981), estes itens agem impedindo rápido decréscimo do $\mathrm{pH}$ a níveis adequados (3,8 a 4,2), fazendo com que fermentações secundárias e indesejáveis ocorram pela ação de bactérias produtoras de ácido butírico, que passarão a se desenvolver utilizando o lactato produzido e açúcares residuais.

Os efeitos negativos do alto teor de umidade foram observados por Faria et al. (1995/96), que, ensilando capim-elefante com teores de matéria seca de 14,34\%, obtiveram teor de nitrogênio amoniacal de $19,59 \%$ e valor de $\mathrm{pH}$ de 4,32. Da mesma forma, Tosi et al. (1995), avaliando o potencial da cv. Mott para ensilagem, encontraram teores de matéria seca de 15,94\%, nitrogênio amoniacal de $23,1 \%$ e $\mathrm{pH}$ de 4,5 . Esses resultados estão acima dos valores preconizados por McDonald (1981) e McCullough (1977), para que ocorra fermentação satisfatória no silo.

Catchapoole \& Henzel (1971) afirmam que algumas forragens tropicais são de difícil ensilagem. Porém, ressaltam que a utilização de aditivos ou técnicas que visem a preservação da forragem antes da ensilagem pode melhorar a fermentação.

Neiva et al. (2001), avaliando a adição de bagaço de caju na ensilagem de capim-elefante, observaram aumento nos teores de proteína bruta, à medida que foi adicionado o subproduto do caju, e decréscimo nos teores de fibra em detergente neutro e de fibra em detergente ácido. Para os valores de $\mathrm{pH}$, observaram média de 3,9 e concluíram que a adição do subproduto do caju proporcionou melhora na conservação e no valor nutritivo das silagens de capim-elefante, pois registraram elevação nos teores de proteína bruta e diminuição nos teores de fibra em detergente neutro e de fibra em detergente ácido.

O presente trabalho foi desenvolvido objetivando-se avaliar o valor nutritivo e as características fermentativas de silagens de capim-elefante (Pennisetum purpureum Schum) com diferentes níveis de adição de bagaço de caju.

\section{Material e Métodos}

O experimento foi conduzido no Núcleo de Pesquisa em Forragicultura do Departamento de Zootecnia da Universidade Federal do Ceará, no município de Fortaleza-CE.

Foram estudados cinco níveis de adição de bagaço de caju $(0,12,24,36$ e 48\%), com base na matéria natural na ensilagem do capim-elefante, utilizando-se o delineamento inteiramente casualizado com quatro repetições.

O capim-elefante foi cortado manualmente quando apresentava aproximadamente 80 dias de idade. Foi emurchecido por 12 horas, processado em picadeira de forragem e, posteriormente, misturado ao bagaço de caju (BC) originado do processamento dos pedúnculos de caju utilizados na fabricação de sucos da empresa MAISA em Mossoró - RN. A composição químico-bromatológica do capim-elefante (Pennisetum purpureum Schum) e do bagaço de caju (Anacardium occidentale L), antes da ensilagem, encontra-se na Tabela 1.

Como silos experimentais, foram utilizados tambores plásticos de 210 L. Após pesagem e homogeneização do material, a forragem foi compactada no interior do silo, durante o carregamento. Completado o enchimento, os silos foram fechados com lonas plásticas, presas com ligas de borracha.

Após 82 dias, os silos foram abertos e retiraramse amostras homogêneas de $300 \mathrm{~g}$ das silagens, que permaneceram armazenadas em congelador a $-10^{\circ} \mathrm{C}$ até a época das análises químico-bromatológicas. Nas amostras das silagens, foram determinados os teores de matéria seca (MS), proteína bruta (PB), fibra em detergente neutro (FDN), fibra em detergente ácido (FDA) e hemicelulose (HEM), por meio de análises realizadas no Laboratório de Nutrição Animal 
da EMBRAPA - Caprinos, no município de Sobral CE, seguindo a metodologia descrita por Silva (1990). Os teores de carboidratos não-fibrosos (CNF) foram obtidos pela fórmula sugerida por Hall (2000), em que: $\mathrm{CNF}=100-(\mathrm{FDN}+\mathrm{PB}+\mathrm{EE}+$ Cinzas $)$. Foram analisados também $\mathrm{pH}$ e nitrogênio amoniacal, no Laboratório de Nutrição Animal do Departamento de Zootecnia da Universidade Federal de Minas Gerais, seguindo a metodologia descrita por Silva (1990).

Antes da realização da análise de variância, os dados foram submetidos aos testes de normalidade e homocedasticidade. As características que não atenderam estas pressuposições foram transformadas para permitir a análise. A transformação utilizada foi a logarítmica e os parâmetros transformados foram teor de proteína bruta e nitrogênio amoniacal.

\section{Resultados e Discussão}

Os teores médios de MS encontram-se na Tabela 2. Foram observadas diferenças $(\mathrm{P}<0,01)$ apenas entre as silagens com 24 e $48 \%$ de BC. Os teores médios de MS das silagens permaneceram, em média, de $23 \%$, portanto abaixo dos $28-34 \%$ sugeridos como ideais por McCullough (1977). O aumento na proporção de $\mathrm{BC}$ nas silagens promoveu efeito quadrático $(\mathrm{P}<0,01)$ sobre os teores de $\mathrm{MS}$, atingindo o teor máximo $(23,75 \%)$ com $18,33 \%$ de BC e reduzindo-se com a adição de 36 e $48 \%$ de BC.

Resultados semelhantes ao deste trabalho foram obtidos por Faria et al. (1972) ao adicionar polpa de laranja fresca ao capim-elefante. Da mesma forma, Kinh et al. (1996) encontraram teores de $22 \%$ de MS para silagens com $100 \%$ de bagaço de caju.

Embora o teor de umidade tenha estado acima dos $75 \%$, aparentemente não se observaram perdas decorrentes de possíveis fermentações indesejáveis (clostrídicas) ou mesmo por apodrecimento comum em silagens úmidas. As silagens apresentaram cheiro agradável e, nas silagens com adição de BC, foi observado o cheiro característico de silagens lácticas.

O BC funcionou, portanto, como eficiente aditivo para silagens úmidas, sendo esperado que sua adição evitasse a perda de matéria seca e, possivelmente, a ação de bactérias indesejáveis (Clostridium), produtoras de ácido butírico e de outros produtos, que diminuem os aspectos qualitativos das silagens.

Tabela 1 - Composição químico-bromatológica do capim-elefante (Pennisetum purpureum Schum) e do subproduto de caju (Anacardium occidentale,L) antes da ensilagem

Table 1 - Chemical composition of elephantgrass (Pennisetum purpureum Schum) and of cashew juice (Anacardium occidentale, L.) by-product before ensilage

\begin{tabular}{lcc}
\hline $\begin{array}{l}\text { Parâmetros (\% MS) } \\
\text { Parameters (\%DM) }\end{array}$ & $\begin{array}{c}\text { Capim-elefante } \\
\text { Elephantgrass }\end{array}$ & $\begin{array}{c}\text { Bagaço de caju } \\
\text { Cashew bagasse }\end{array}$ \\
\hline $\begin{array}{l}\text { Matéria seca } \\
\text { Dry matter }\end{array}$ & 25,6 & 25,4 \\
$\begin{array}{l}\text { Matéria orgânica } \\
\text { Organic matter }\end{array}$ & 83,2 & 91,6 \\
$\begin{array}{l}\text { Proteína bruta } \\
\text { Crude protein }\end{array}$ & 3,3 & 14,2 \\
$\begin{array}{l}\text { Extrato etéreo } \\
\text { Ether extract }\end{array}$ & 2,2 & 4,1 \\
$\begin{array}{l}\text { Fibra detergente neutro } \\
\text { Neutral detergent fiber }\end{array}$ & 76,7 & 65,5 \\
$\begin{array}{l}\text { Fibra detergente ácido } \\
\text { Acid detergentfiber }\end{array}$ & 46,6 & 47,0 \\
$\begin{array}{l}\text { Hemicelulose } \\
\text { Hemicellulose } \\
\text { Celulose } \\
\text { Cellulose }\end{array}$ & 29,4 & 18,5 \\
$\begin{array}{l}\text { Lignina } \\
\text { Lignin } \\
\text { Carboidratos não-fibrosos }\end{array}$ & 38,4 & 24,3 \\
Nonfiber carbohydrates & 3,2 & 22,5 \\
\end{tabular}

R. Bras. Zootec., v.33, n.6, p.1380-1385, 2004 
Os teores médios de PB são apresentados na Tabela 2. Observou-se que as silagens contendo 36 e $48 \%$ de $\mathrm{BC}$ foram semelhantes e apresentaram teores de $\mathrm{PB}$ superiores $(\mathrm{P}<0,01)$ às demais. As silagens com $0 \%$ de $\mathrm{BC}$ e aquela contendo $12 \%$ de BC apresentaram níveis de PB inferiores aos 7\% considerados como nível mínimo para que haja bom funcionamento ruminal (Van Soest, 1994).

No estudo de regressão, observou-se comportamento quadrático $(\mathrm{P}<0,01)$ sendo que inicialmente os valores elevaram-se em razão da adição de $\mathrm{BC}$ e tenderam a se estabilizar na silagem com $48 \%$ de BC, como observado na Tabela 2. O teor máximo $(9,55 \%)$ de $\mathrm{PB}$ foi obtido, com adição de $47,75 \%$ de BC. Como o BC apresenta teores de PB maiores que o capim-elefante, era de se esperar que a adição do mesmo aumentasse linearmente os teores de PB da silagem, conforme observado por Neiva et al. (2001). Ocorre que, em decorrência da prensagem do material para extração do suco, quando adicionado em alta proporção (48\%), o BC formou placas dentro do silo e, na retirada manual das amostras, gerando amostras com maiores proporções de capim, pois tais placas, ao contrário do capim, não se desfazem facilmente.
A adição de $36 \%$ de $\mathrm{BC}$ ao capim-elefante possibilitou incremento de 6,0 unidades percentuais de PB, ou seja, um aumento de $63 \%$ no teor de PB, em comparação à silagem com $0 \%$ de BC. Resultados semelhantes foram observados por Neiva et al. (2001) que constataram elevação nos teores de proteína bruta das silagens, com adição de BC na ensilagem do capim-elefante. Dessa forma, a adição de BC, na ensilagem do capim-elefante, pode funcionar como eficiente fonte de nitrogênio, melhorando as características nutricionais da silagem.

Os teores médios de FDN, FDA e HEM encontram-se na Tabela 2. Quanto aos teores de FDN, observou-se que as silagens com $36 \%$ de BC apresentaram o menor nível $(73,42 \%)$, diferindo das demais $(\mathrm{P}<0,01)$. Pelo estudo de regressão, foi possível constatar comportamento quadrático $(\mathrm{P}<0,01)$, em que os teores de FDN atingem valores mínimos (74,9\%), com adição de 37,5\% de BC, elevando-se com adição de $48 \%$ de BC (Tabela 2). Para os teores de FDA e HEM, não se observou diferença entre as silagens. Esses dados contrariam os relatos de Neiva et al. (2001), que observaram redução linear nos níveis de FDN e FDA com o acréscimo de BC às silagens.

Tabela 2 - Percentuais médios de matéria seca (MS), proteína bruta (PB), fibra em detergente neutro (FDN), fibra em detergente ácido (FDA), hemicelulose (HEM), extrato etéreo (EE), nitrogênio amoniacal $\left(\mathrm{N}-\mathrm{NH}_{3}\right)$ e valores de $\mathrm{pH}$ das silagens de capim-elefante com níveis crescentes de adição de bagaço de caju

Table 2 - Levels of dry matter (DM), crude protein (PB), neutral detergent fiber (NDF), acid detergent fiber (ADF), hemicellulose (HEM), ether extract $(E E)$, ammoniacal nitrogen $\left(\mathrm{N}-\mathrm{NH}_{3}\right)$ and $\mathrm{pH}$ of elephantgrass silage with increasing levels of cashew bagasse

\begin{tabular}{|c|c|c|c|c|c|c|c|}
\hline \multirow[b]{2}{*}{$\begin{array}{l}\text { Parâmetros (\%MS) } \\
\text { Parameters (DM) }\end{array}$} & \multicolumn{5}{|c|}{$\begin{array}{l}\text { Nível de adição de bagaço de caju } \\
\text { Levels of addition of cashew bagasse }\end{array}$} & \multirow[b]{2}{*}{$\begin{array}{l}\text { Regressões } \\
\text { Regressions }\end{array}$} & \\
\hline & $0 \%$ & $12 \%$ & $24 \%$ & $36 \%$ & $48 \%$ & & \\
\hline $\begin{array}{l}\text { MS } \\
D M\end{array}$ & $23,1 \mathrm{ab}$ & $23,2 \mathrm{ab}$ & $24,6 \mathrm{a}$ & $23,0 \mathrm{ab}$ & $21,8 b$ & $Y=22,85+0,11 X-0,003 X^{2}$ & $\mathrm{R}^{2}=0,93$ \\
\hline $\begin{array}{l}\mathrm{PB} \\
C P\end{array}$ & $3,6 \mathrm{~d}$ & $5,28 \mathrm{c}$ & $7,5 b$ & $9,6 \mathrm{a}$ & $9,5 \mathrm{a}$ & $\log (Y)=0,54+0,02 X-0,002 X^{2}$ & $\mathrm{R}^{2}=0,95$ \\
\hline $\begin{array}{l}\text { FDN } \\
N D F\end{array}$ & $77,2 \mathrm{a}$ & $75,2 \mathrm{a}$ & $76,6 \mathrm{ab}$ & $73,4 \mathrm{c}$ & $75,2 b$ & $(Y)=77,12-0,12 X+0,24 X^{2}$ & $\mathrm{R}^{2}=0,19$ \\
\hline $\begin{array}{l}\text { FDA } \\
A D F\end{array}$ & 48,0 & 44,0 & 47,4 & 43,2 & 50,2 & $Y=46,5$ & \\
\hline $\begin{array}{l}\text { HEM } \\
\text { HEM }\end{array}$ & 29,2 & 31,2 & 29,3 & 30,2 & 25,3 & $Y=29,0$ & \\
\hline $\begin{array}{l}\mathrm{pH} \\
\mathrm{pH}\end{array}$ & $4,7 \mathrm{a}$ & $4,3 b$ & $4,2 \mathrm{bc}$ & $4,2 \mathrm{c}$ & $4,2 \mathrm{c}$ & $(Y)=4,63+0,025 X-0,00034 X^{2}$ & $\mathrm{R}^{2}=0,84$ \\
\hline $\begin{array}{l}\mathrm{N}-\mathrm{NH}_{3} \\
\mathrm{~N}-\mathrm{NH}_{3}\end{array}$ & $13,2 \mathrm{a}$ & $6,2 b$ & $4,0 \mathrm{c}$ & $3,5 \mathrm{c}$ & $3,1 \mathrm{c}$ & $\log (Y)=1,1-0,03 X+0,00035 X^{2}$ & $\mathrm{R}^{2}=0,92$ \\
\hline
\end{tabular}

Médias seguidas de letras diferentes, na mesma linha, diferem entre si $(P<0,01)$, pelo teste Duncan.

Means followed by different letters, in same row, differ $(P<.01)$ by Duncan test.

R. Bras. Zootec., v.33, n.6, p.1380-1385, 2004 
Entretanto, como o BC, na pré-ensilagem, apresentaram teores de FDN $(65,47 \%)$ e HEM $(18,48 \%)$ inferiores ao registrado para o capimelefante pré-ensilado, FDN (76,73) e HEM $(29,35)$, esperava-se que houvesse redução progressiva nos níveis de FDN e HEM, por efeito da substituição do capim-elefante pelo BC. Estes resultados podem estar relacionados a problemas de amostragem, item comentado anteriormente.

Foi observada tendência de diminuição dos valores de $\mathrm{pH}$ (Tabela 2), à medida que o BC foi incluído na silagem, observando-se valor mínimo $(4,17)$ com adição de $36,76 \%$ de BC. As silagens com 24, 36 e $48 \%$ mostraram-se equivalentes e apresentaram valores dentro da faixa de 3,8 a 4,2, considerada típica de silagens bem preservadas (McDonald, 1981). A silagem com $0 \%$ de $\mathrm{BC}$ apresentou $\mathrm{pH}$ superior $(\mathrm{P}<0,01)$ às demais.

Os menores valores de $\mathrm{pH}$ nas silagens contendo $\mathrm{BC}$ podem ser explicados pela maior disponibilidade de carboidratos solúveis no $\mathrm{BC}$, conduzindo, possivelmente, à produção de ácido lático, provocando queda mais rápida do $\mathrm{pH}$. Outra explicação seria a presença de ácido málico no pseudofruto, que, embora exerça alto poder tampão, apresenta baixo $\mathrm{pH}$, contribuindo para acidificação da silagem (Menezes \& Alves, 1995).

A partir dos resultados obtidos para valores de $\mathrm{pH}$ e $\mathrm{N}-\mathrm{NH}_{3}$, pode-se admitir ausência de fermentações secundárias resultantes da ação das bactérias do gênero Clostridium, que, em meio favorável ao seu desenvolvimento, conduzem ao desdobramento de aminoácidos, com produção de ácido butírico, ácidos voláteis, aminas, amônia e gases, prejudicando o valor nutritivo da silagem (McDonald, 1981).

No tocante ao nitrogênio amoniacal, como porcentagem do nitrogênio total $\left(\mathrm{N}^{-\mathrm{NH}_{3}}\right)$ (Tabela 2$)$, verificou-se que as silagens com adição de $\mathrm{BC}$ reduziram $(\mathrm{P}<0,01)$ os teores de $\mathrm{N}-\mathrm{NH}_{3}$ para níveis inferiores a $12 \%$, com o ponto mínimo $(2,75 \%)$ observados com $44,11 \%$ de BC, classificando-as como silagens de boa qualidade, segundo McDonald (1981).

$\mathrm{O}$ comportamento dos parâmetros $\mathrm{pH}$ e N-NH apresentou-se de forma quadrática $(\mathrm{P}<0,01)$, em função dos níveis de adição de BC. A curva demonstrou que os menores valores de $\mathrm{pH}$ acompanharam os menores teores de $\mathrm{N}-\mathrm{NH}_{3}$ nas silagens com 24,36 e $48 \%$ de BC (Tabela 2).

Utilizando resíduos de agroindústria, Reis (1994) também encontrou valores de $\mathrm{pH}$ e N-NH 3 dentro do nível considerado ideal para uma silagem bem preservada. Faria et al. (1972), avaliando a inclusão de polpa seca de laranja ao capim-elefante, observaram valores de $\mathrm{pH}$ de 4,07 a 4,46, semelhantes aos observados neste trabalho. Resultados semelhantes para teores de $\mathrm{N}-\mathrm{NH}_{3}$ foram relatados por Neiva et al. (1999), que, ao avaliarem o uso de cana-de-açúcar desidratada como aditivo na ensilagem de capimelefante, encontraram teores de $4,5 \%$ de $\mathrm{N}^{-\mathrm{NH}_{3}}$, e Silva et al. (1999), que registraram teores de 3,17; 2,99 e 3,28\% de $\mathrm{N}^{-\mathrm{NH}_{3}}$, em silagens de sorgo.

Este resultado confirma a importância do BC como fonte de carboidratos, contribuindo para obtenção de silagens de gramíneas tropicais com melhores características fermentativas. O BC utilizado no presente trabalho apresentou teor de carboidratos não-fibrosos (CNF) de 11,9\% (Tabela 1), enquanto o capim- elefante, de apenas 3,2\%. Dessa forma, pode-se inferir que a melhoria nas características fermentativas das silagens contendo BC deve-se, principalmente, ao maior teor de CNF do mesmo.

\section{Conclusões}

O bagaço de caju pode ser utilizado como aditivo na ensilagem de capim-elefante, melhorando as características fermentativas da silagem, com elevação no teor de PB e redução dos teores de FDN, sendo recomendada a adição de até $47,7 \%$ de BC para se obter o nível máximo de $\mathrm{PB}$ e, aproximadamente, $37,5 \%$ de adição de $\mathrm{BC}$ para atingir o menor nível de FDN.

\section{Literatura Citada}

AWOLUMATE, E.O. Chemical composition and potential uses of processing wastes from some Nigerian cash crops. Turrialba, v.33, n.4, p.281-386, 1983.

CATCHAPOOLE, V.R.; HENZEL, E.F. Silage and silage-making from tropical herbage species. Herbage Abstracts, v.41, n.3, p.213-221, 1971.

FARIA, E.F.S.; GONÇALVES, L.C.; ANDRADE. V.J. Comparação de seis tratamentos empregados para melhorar a qualidade da silagem da capim-elefante (Pennisetum purpureum Schum.) em três idades de rebrota. I - 60 dias. Arquivo Escola de Medicina Veterinária da UFBA, v.18, n.1, p.103-125, 1995/96.

FARIA, V.P.; TOSI, H.; GODOY, C.R.M. Polpa de laranja fresca e seca como aditivos para a ensilagem do capimelefante Napier (Pennisetum purpureum). O Solo, v.64, n.1, p.41-47, 1972.

HALL, M.B. Neutral detergent-soluble carbohydrates. Nutritional relevance and analysis. Florida: University of Florida, 2000. (Bulletin, 339)

R. Bras. Zootec., v.33, n.6, p.1380-1385, 2004 
HOLANDA, J.S.; FURUSHO, I.F.; LIMA, G.F.C. et al. Perspectivas de uso do pedúnculo de caju na alimentação animal. In: SIMPÓSIO NORDESTINO DE RUMINANTES, 6., 1996, Natal. Anais... Natal: Sociedade Nordestina de Produção Animal, 1996. p.155-161.

KINH, L.V.; DO, V.V.; PHUONG, D.D. Chemical composition of cashew apple and cashew apple waste ensiled with poultry litter. Livestock Research for Rural Development. v.9, n.1, p.125-130, 1996.

LAVEZZO, W. Silagem de capim-elefante. Informe Agropecuário, v.11, n.132, p.50-57, 1985.

LAVEZZO, O.E.N.M. Abacaxi, banana, caju, uva, maçã. In: SIMPOSIO SOBRE NUTRIÇÃO DE BOVINOS, 6., 198-, Piracicaba. Anais... Piracicaba: Escola Superior de Agricultura Luiz de Queiroz, 198-. p.7-46.

MENEZES, J.B.; ALVES, R.E. Fisiologia e tecnologia póscolheita do pedúnculo do caju. Fortaleza: EMBRAPA Centro Nacional de Pesquisa Agroindústria Tropical, 1995. 20p. (Documento, 17)

McDONALD, P. The biochemistry of silage. New York: John Willey \& Sons. 1981. 226p.

McCUlLOUGH, M.E. Silage and silage fermentation. Feedstuffs, v.49, n.13, p.49-52, 1977.

NEIVA, J.N.M.; FERREIRA, A.C.H.; VASCONCELOS, V.R., et al. Use of dehydrated sugar cane (Saccharum officinarum L.) as additive to Napier grass (Pennisetum purpureum Schum) ensilage. In: SILAGE MAKING IN THE TROPICS WITH PARTICULAR EMPHASIS ON SMALLHOLDERS, 161., 1999, Rome. Proceedings... Rome: FAO, 1999. p.167-168.

NEIVA, J.N.M.; TEIXEIRA, M.C.; LÔBO, R.N.B. et al. Avaliação do valor nutritivo de silagens de capim-elefante (Pennisetum purpureum Schum). com diferentes níveis de subproduto de pseudofruto do caju (Anacardium ocidentale) In: REUNIÃO ANUAL DA SOCIEDADE BRASILEIRA DEZOOTECNIA, 37., 2001, Piracicaba. Anais ... Piracicaba: Sociedade Brasileira de Zootecnia, 2001. p.1-3.
REIS, J. Composição química, consumo voluntário e digestibilidade das silagens de resíduos do fruto de maracujá (Passiflora edulis) com capim-elefante, cv Camerron e suas combinações. Lavras: Escola Superior de Agricultura de Lavras, 1994. 53p. Dissertação ( Mestrado em Zootecnia) - Escola Superior de Agricultura de Lavras, 1994.

SILVA, F.F.; GONÇALVES, L.C.; RODRIGUES, J.A.S. et al. Qualidade de silagens de híbrido de sorgo ( Soghum bicolor (L.) Moench) de portes baixo, médio e alto com diferentes proporções de colmo folhas/panícula.1. Avaliação do processo fermentativo. Revista Brasileira de Zootecnia, v.28, n.1, p.14-20, 1999.

SILVA, D.J. Análise de alimentos: métodos químicos e biológicos. Viçosa, MG: Universidade Federal de Viçosa, 1990. 165p.

TOSI, H.; RODRIGUES, L.R.A.; JOBIM, C.C. et al. Ensilagem do capim-elefante cv. Mott sob diferentes tratamentos. Revista Brasileira de Zootecnia, v.24, n.6, p.909-916, 1995.

Van SOEST, P.J. Nutritional ecology of the ruminant. 2.ed. New York: Cornell University Press, 1994. 476p.

Recebido em: 10/06/03

Aceito em: 16/02/04 